\title{
Genital tuberculosis in infertile women: role of hysterolaparoscopy and tuberculosis polymerase chain reaction
}

\author{
Nikita Gandotra ${ }^{1}$, Abhinav Sharma ${ }^{2 *}$, Preeti Sharma ${ }^{3}$ \\ ${ }^{1}$ Department of Obstetrics and Gynecology, SMGS Jammu, J\&K, India \\ ${ }^{2}$ Department of Pulmonary Medicine and Critical Care, Jammu, J\&K, India \\ ${ }^{3}$ Department of Obstetrics and Gynecology, RPGMC Tanda, Himachal Pradesh, India \\ Received: 05 May 2019 \\ Accepted: 11 June 2019 \\ *Correspondence: \\ Dr. Abhinav Sharma, \\ E-mail: nikigandotra@gmail.com \\ Copyright: () the author(s), publisher and licensee Medip Academy. This is an open-access article distributed under \\ the terms of the Creative Commons Attribution Non-Commercial License, which permits unrestricted non-commercial \\ use, distribution, and reproduction in any medium, provided the original work is properly cited.
}

\begin{abstract}
Background: Genital tuberculosis is an important cause of female infertility in developing countries like India. It is one of the major causes for severe tubal disease leading to infertility.

Methods: A prospective study was conducted in which 100 women presented to hospital with infertility were subjected to hystero-laparoscopy over 1 year. Endometrium sent for tuberculosis polymerase chain reaction (TBPCR) and HPE and results were formulated.

Results: Out of 100 women, $28 \%$ were diagnosed with Genital tuberculosis (GTB) using accepted clinical criteria, TB-PCR and endometrial HPE. 25 of these 28 were diagnosed by hysterolaparoscopy $(89.24 \%)$ alone, 16 by positive endometrial TB-PCR (57.14\%) and another 2 by HPE (7.14\%).

Conclusions: In country like ours where TB is endemic, a multi-pronged approach to diagnosis increases the chances of successfully diagnosing this destructive disease.
\end{abstract}

Keywords: Genital tuberculosis, Tuberculosis Polymerase chain reaction

\section{INTRODUCTION}

Infertility has always been one of the most elusive symptom complexes that perplex the best gynecologists and affects about $10-15 \%$ of reproductive age couples. Genital TB in females is well recognized as an important etiological factor for infertility in countries with high prevalence of TB. India is the highest TB burden country with WHO statistics giving an estimated incidence figure of 2.2 million cases of TB out of a global incidence of 9.6 million cases, of which 3.2 million were among women. ${ }^{1}$

About $9 \%$ of all extra- pulmonary tuberculosis cases are genital tract TB. ${ }^{2}$ Other clinical presentations of genital TB include oligomenorrhoea (54\%), amenorrhea (14\%), menorrhagia (19\%), abdominal pain (42.5\%), dyspareunia (5-12\%) and dysmenorrhea (12-30\%). The worldwide incidence of GTB is approximately $5-10 \%$ in infertile women. It varies from as low as $0.69 \%$ in some developed countries to as high as $19 \%$ in India. ${ }^{3}$ Genital TB usually occurs secondary to $\mathrm{TB}$ in other sites (primarily, the lungs). ${ }^{4}$ The spread is generally through haematogenous or lymphatic routes. ${ }^{5}$

The diagnostic dilemma arises due to varied clinical presentation, diverse results on imaging and endoscopy and availability of battery of bacteriological, serological and histopathological tests which are often required to get a collective evidence of the diagnosis of genital TB. ${ }^{6}$ Laparoscopy is the most reliable tool to diagnose genital TB, especially for tubal, ovarian and peritoneal disease. Hysteroscopy permits direct visualization of the cervical 
canal and uterine cavity, enabling observation of the shape and vascular pattern of any abnormality. In addition, hysteroscopic approach offers the possibility of obtaining endometrial biopsies under visual control. DNA- Polymerase Chain Reaction (PCR) is now affordable and a much more reliable test for rapid and improved diagnosis. Infertile women without tubal or endometrial damage given early anti-tuberculosis treatment, based on a positive endometrial TB-PCR test, have an excellent chance of early spontaneous conception. $^{7}$ The advantage of this test is that it reveals the false negative, because each amplification provides an internal control for the other and false positives are also reduced due to amplification of targeted genes. For the same reason, PCR has been able to detect TB bacilli in the concentration as low as 10 bacilli $/ \mathrm{ml}^{8}$ Hence in combination with accurate clinical assessment and endoscopy, PCR test seems to be a very promising diagnostic tool.

\section{METHODS}

A prospective study was carried out between September 2017 to September 2018 on 100 women presenting with infertility in the department of obstetrics and gynecology, SMGS hospital Jammu after taking clearance from ethical committee. Detailed history was taken, clinical examination, haematological investigations, pelvic ultrasound, semen analysis, hormonal assays were done. Hysterosalpingogram (HSG) was not done in our study, but the images of women who already had such an investigation were reviewed for tubercular findings. A past history of tuberculosis as well as Anti tubercular drug use was noted in detail, along with any history of tubercular contact.

\section{Inclusion criteria}

- Married women of reproductive age group with primary/secondary infertility willing for infertility workup

- Normal semen analysis of husband.

\section{Exclusion criteria}

- Patients with male factor infertility

- Patients with anovulation (detailed hormonal analysis)

- Couples who have not lived together for 12 months.

- Patients with absolute/relative contraindications for laparoscopy or hysteroscopy

- Patients not willing for surgery.

- GTB associated with co-morbid conditions like medical disorders, HIV, cancers were also excluded.

The All 100 selected women were posted for diagnostic hystero-laparoscopy after written informed consent. Preanaesthethic evaluation was carried out in the evening and preparation of the patient for hysteroscopy and laparoscopy was done. Prophylactic antibiotic was given a night before and at the time of induction. Endometrial curettage was done during the procedure and the sample was sent for histopathology and the specialized laboratory for TB-PCR. Laparoscopic findings like tubal blocks, peritubal adhesions, hydrosalpinges, tubo-ovarian masses and tubercles were noted. Hysteroscopic findings like cervical stenosis, narrow uterine cavity, endometrial bands and synechia, blocked tubal ostia, scanty endometrium and tubercles in the endometrium were documented. In our study, we sent endometrial TB-PCR of all women, irrespective of hystero- laparoscopic findings. Chest physician consultation was sought for all selected females.

Gross appearance of healthy endometrial cavity on hysteroscopy and normal pelvic findings on laparoscopy were the criteria used to exclude GTB. These findings again correlated with clinical history, detailed examination and additional endometrial TB-PCR. Data was entered using Statistical Package for Social Sciences and in Microsoft excel software. Continuous variables were summarized in the form of mean and standard deviation. Categorical variables were summarized as percentage. Frequency distribution tables, bar charts and pie charts were used for data presentation.

\section{RESULTS}

Out of 100 patients included in the study, 67 (67\%) women presented with primary infertility and 33 women (33\%) presented with secondary infertility). Out of $33 \%$ women presenting with secondary infertility, 22 (66.6\%) patients had history of previous abortions out of which, $16(48.5 \%)$ patients had history of previous one abortion, $5(15.1 \%)$ patients had history of previous two abortions and $1(3.03 \%)$ patient had history of previous three abortions. $1(3.03 \%)$ patient had history of previous intrauterine death at term. 10 patients $(30.3 \%)$ had history of previous uneventful delivery (Table 1).

Table 1: Distribution of patients according to the type of infertility.

\begin{tabular}{|lll|}
\hline Type of infertility & No. & $\%$ \\
\hline Primary & 67 & $67 \%$ \\
\hline Secondary & 33 & $33 \%$ \\
\hline Total & 100 & $100 \%$ \\
\hline
\end{tabular}

Mean age at presentation for primary infertility in pour study was $28.6 \pm 4.20$ years and for secondary infertility, it was $32.1 \pm 3.84$ years. Mean duration of infertility in the patients of primary and secondary infertility was $3.4 \pm 1.82$ years and $4.8 \pm 2.26$ years respectively (Table 2 ).

Most common menstrual abnormality in the infertile patients included in the study was menorrhagia $(11 \%)$ followed by oligomenorrhea $(9 \%)$ and dysmenorrhea (9\%).Out of 100 infertile females, 28 (28\%) women were diagnosed as genital tuberculosis by combination of hysteron-laparoscopic findings

$(25 / 28)$ 
histopathological2/28) and endometrial DNA-PCR (16/28). PCR was positive in 22 patients, 6 out of whom had normal hysterolaparoscopy. Out of these 28 women, $11(39.28 \%)$ had secondary infertility and remaining 17
$(60.71 \%)$ had primary infertility. 4 (14.28\%) were previously diagnosed with pulmonary or extra pulmonary tuberculosis and had completed a full course of Antitubercular treatment (Table 3 ).

Table 2: Age distribution of infertile patients.

\begin{tabular}{|c|c|c|c|c|c|c|}
\hline \multirow{2}{*}{ Age } & \multicolumn{2}{|c|}{ Primary } & \multicolumn{2}{|c|}{ Secondary } & \multicolumn{2}{|c|}{ Total } \\
\hline & No. & $\%$ & No. & $\%$ & No. & $\%$ \\
\hline $20-25$ & 8 & $11.9 \%$ & 2 & $6.1 \%$ & 10 & $10 \%$ \\
\hline $25-30$ & 33 & $49.3 \%$ & 5 & $15.2 \%$ & 38 & $38 \%$ \\
\hline $30-35$ & 18 & $26.9 \%$ & 16 & $48.5 \%$ & 34 & $34 \%$ \\
\hline$\geq 35$ & 8 & $11.9 \%$ & 10 & $30.3 \%$ & 18 & $18 \%$ \\
\hline Total & 67 & $100 \%$ & 33 & $100 \%$ & 100 & $100 \%$ \\
\hline Mean \pm SD & \multicolumn{2}{|c|}{$28.6 \pm 4.20$} & \multicolumn{2}{|c|}{$32.1 \pm 3.84$} & \multicolumn{2}{|c|}{ P-value $<0.001^{*}$} \\
\hline
\end{tabular}

Table 3: Mode of diagnosis of genital TB.

\begin{tabular}{|ll|}
\hline Mode of diagnosis & No. of patients diagnosed \\
\hline Hystero-laparoscopy & $25 / 28(89.28 \%)$ \\
\hline TB PCR positive & $16 / 28(57.14 \%)$ \\
\hline HPE & $2 / 28(7.14 \%)$ \\
\hline
\end{tabular}

Table 4: Laparoscopic and hysteroscopic findings in 100 infertile females.

\begin{tabular}{|ll|}
\hline Laparoscopic findings & No. $(\%)$ \\
\hline Normal & 72 \\
\hline Periovarian adhesions & $6(21.42 \%)$ \\
\hline Cornual block & $3(10.71 \%)$ \\
\hline Tubal beading & $4(14.28 \%)$ \\
\hline Peritubal adhesions & $3(10.71)$ \\
\hline Delayed spill & $2(7.14 \%)$ \\
\hline Perihepatic adhesions & $1(3.57 \%)$ \\
\hline Tubercles & $2(7.14 \%)$ \\
\hline U/L Tubo-ovarian mass & $1(3.57 \%)$ \\
\hline Fimbrial block & $1(3.57 \%)$ \\
\hline Hydrosalpinx & $1(3.57 \%)$ \\
\hline Bowel and omental adhesions & $4(14.28 \%)$ \\
\hline Fimbrial phimosis & $1(3.57 \%)$ \\
\hline Associated endometriosis & $4(14.28 \%)$ \\
\hline Associated PCOD & $3(10.71 \%)$ \\
\hline Hysteroscopic findings & \\
\hline Fibrosed ostia & $4(14.28 \%)$ \\
\hline Intrauterine adhesions & $2(7.14 \%)$ \\
\hline Small uterine cavity & $1(3.57 \%)$ \\
\hline
\end{tabular}

There were $89.28 \%(25 / 28)$ had findings pointing towards TB on hystero- laparoscopy, such as beaded tubes, peritubal adhesions, frozen pelvis, blocked tubes, tubercles on the pelvic organs. Hysteroscopic findings mainly suggestive of tuberculosis were fibrosed endometrium, narrow cavity and intrauterine adhesions. However, only in 16/28 (57.14\%) patients TB-PCR were positive. PCR was positive in 13 out of 25 endoscopy positive patients and 9 PCR positive patients had normal endoscopy findings (Total=22 PCR + ). Sensitivity and
Specificity of TB PCR in our study was $5.17 \%$ and $91.6 \%$ respectively. $2(7.14 \%)$ females had positive histopathological findings suggestive of TB (Table 4).

Acid fast bacilli (AFB) culture was sent for all patients in present study. Out of 4 suspected patients of tuberculosis on laparoscopy, AFB culture was positive in 2 patients $(7.14 \%)$ and in rest of the patients, AFB culture was negative.

\section{DISCUSSION}

In the present study, out of 100 infertile patients, $67 \%$ (67) presented with primary infertility and 33\% (33) presented with secondary infertility. It was comparable with studies conducted by Nayak KP et al, Shetty KS et al, Vaid $\mathrm{K}$ et al, and Shah JS et al. ${ }^{9-12}$ Tuberculosis of female genital tract involves the fallopian tubes, the endometrial cavity and the ovaries; cervical and vaginal disease is rare. Genital TB has been associated with 0.2 to $21 \%$ of infertility cases, mostly among women in resource limited settings. ${ }^{13}$ Classically, GTB has been described inevitably as a disease of reproductive age women. The presenting symptoms are related to menstrual irregularities and infertility. Hence early diagnosis and treatment will improve fertility outcome. Out of 100 infertile patients, 28 (28\%) patients had findings suggestive of Tuberculosis which was comparable to study conducted by Shende $\mathrm{P}$ et al, (27\%). ${ }^{14}$ In the present study, $57.14 \%$ positive TB-PCR results were comparable with a study by Bhanu NV et al, (56\%) 8 and Shende P et al (58\%). ${ }^{14}$ While Puri et al, had $46.67 \%$ positive TB PCR results. ${ }^{15}$ Hystero-laparoscopy was diagnostic in about $89.24 \%$ of confirmed cases in our study while studies conducted by Baxi et al, had $42.52 \%$, Shende $\mathrm{P}$ et al had 93\%, and Sharma et al, had $47 \%$ confirmed cases. ${ }^{7,14,16}$ Diagnosing GTB by presence of granulomatous lesions on HPE is difficult due to cyclic shedding of endometrium. A study by conducted by Shende $\mathrm{P}$ et al revealed $10 \%$ of GTB cases on endometrial HPE and study by Bapna et al, documented $12.5 \%$ women of GTB having positive histopathological 
reports. ${ }^{14,17}$ In our study, HPE was diagnostic in $7.14 \%$ of GTB cases. Genital tuberculosis is an important cause of female infertility in developing countries like India. Unlike pulmonary tuberculosis, diagnosis of genital tuberculosis is difficult because in majority of cases the disease is either asymptomatic or has varied clinical presentation. ${ }^{13}$ Hysterolaparoscopy is a valuable tool for diagnosing tubal infertility as well genital TB.

The principal weakness of this study is that TB PCR test, considered as a gold standard for assessment of endoscopic features, is not $100 \%$ sensitive and specific. Like any other bacteriological test available for diagnosing $\mathrm{TB}$, it is known to give a small number of false-positive and -negative results. Secondly, for the endoscopic features which are considered suggestive of $\mathrm{TB}$, there are no defined criteria in literature. On the basis of microscopic as well as macroscopic pathogenesis of mycobacterial infection and the endoscopic features known to be strongly associated with genital TB, assessment criteria were defined for the present study and combining it with TB PCR and HPE sensitivity can be improved. ${ }^{7}$

\section{CONCLUSION}

Hysterolaparoscopy is an effective and safe tool in comprehensive evaluation of female infertility, particularly for detecting peritoneal endometriosis, ovarian pathologies, adnexal adhesions and abnormalities in the uterus. GTB being secondary to other sites like lungs and lymph nodes is often insidious and asymptomatic. Pathognomonic appearances on hysterolaparoscopy strongly point in the direction of GTB and TB-PCR is a reliable diagnostic tool. ATT started early, may give a significant advantage in improving the chances of conception. Therefore, in countries where TB is endemic, a Multi-pronged approach to diagnosis increases the chances of successfully diagnosing this destructive disease.

\section{ACKNOWLEDGMENTS}

Authors would like to thank all the patients for their cooperation for the study.

Funding: No funding sources Conflict of interest: None declared

Ethical approval: The study was approved by the Institutional Ethics Committee

\section{REFERENCES}

1. WHO Global TB Control Report. 20th edition. 2015. Available at: http://www.who.int/tb/publications /global_report/gtb r15_main_text.pdf.

2. Bose $\bar{M}$. Female genital tract tuberculosis: How long will it elude diagnosis? Indian J Med Res. 2011;134(1):13-4.

3. Figueroa-Damian R, Martinez-Velazco I, VillagranaZesati R. Tuberculosis of the female reproductivetract: effect on function. Int $\mathrm{J}$ Fertil Menopausal Stud. 1996;41(4):430-6.

4. Schaefer G. Female genital tuberculosis. Clin Obstet Gynecol. 1976;19:223-39.

5. Sharma JB. Tuberculosis and obstetric and gynecological practice. In: Studd J, Tan SL, Chervenak FA, editors. Progress Obstet Gynaecol. 2008;18:395-427.

6. Sharma JB. Current diagnosis and management of female genital tuberculosis. J Obstet Gynaecol India. 2015;65:36271.

7. Baxi A. Genital tuberculosis in infertile women: assessment of endometrial TB PCR results with laparoscopic and hysteroscopic features. J Obstetrics Gynecol India. 2011:301-306.

8. Bhanu NV, Singh UB, Chakraborty M. Improved diagnostic value of PCR in the diagnosis of female genital tuberculosis leading to infertility. J Med Microbiol. 2005;54(Pt10):927-31.

9. Nayak KP, Mahapatra CP, Mallick JJ, Swain S, Mitra S, Sahoo J. Role of diagnostic hysterolaparoscopy in the evaluation of infertility: A retrospective study of 300 patients. J Hum Reprod Sci. 2012;6(1):32-4.

10. Shetty KS, Shetty H, Rai S. Laparoscopic evaluation of tubal factor in cases of infertility. Int J Reprod Contracept Obstet Gynecol. 2013;2(3):410-3.

11. Vaid K, Mehra S, Verma M, Jain S, Sharma A, Bhaskaran S. Pan endoscopic approach "Hysterolaparoscopy" as an initial procedure in selected infertile women. J Clinic Diagnos Res. 2014;8(2):95-8

12. Shah SJ, Shah AC, Trivedi YN. Study of combined Laparoscopic and Hysteroscopic findings in 100 cases of Infertility. NHL J Med Sci. 2014;3(2).

13. Mondal SK. A ten year study of female genital tuberculosis and impact on fertility. JNMA J Nepal Med Assoc. 2009;48:52.

14. Shende P, Valecha SM, Gandhewar M, Dhingra D. Genital tuberculosis and infertility. Int J Reprod Contracept Obstet Gynecol. 2017;6(8):3514-3517

15. Suman P, Bhavana B. Diagnostic value of PCR in female genital TB and its therapeutic implications. J Obstet Gynecol India. 2009;59(1):67-70.

16. Sharma JB, Roy KK, Pushparaj M, Kumar S, Malhotra N, Mittal S. Laparoscopic female genital tuberculosis. Arch Gynecol Obstet. 2008;278(4):359-64.

17. Neelam B, Mohanlal S, Namita K. Genital tuberculosis and its consequences on subsequent fertility. J Obstet Gynecol India. 2005;55(6):534-7.

Cite this article as: Gandotra N, Sharma A, Sharma

P. Genital tuberculosis in infertile women: role of hysterolaparoscopy and tuberculosis polymerase chain reaction. Int J Reprod Contracept Obstet Gynecol 2019;8:2781-4. 